\title{
Optimization of steam explosion parameters for improved biotechnological use of wheat straw
}

\author{
Daniel Sulzenbacher ${ }^{1}$ - Denise Atzmüller ${ }^{2} \cdot$ Felix Hawe $^{1} \cdot$ Manuela Richter $^{1}$ • Alvaro Cristobal-Sarramian ${ }^{1}$. \\ Alexander Zwirzitz $^{1}$ (B)
}

Received: 8 September 2020 / Revised: 22 December 2020 / Accepted: 29 December 2020 / Published online: 12 January 2021

(C) The Author(s) 2021

\begin{abstract}
Using lignocellulosic raw materials as substrate for biotechnological applications has been a focus of research during the last two decades. They contain sugars, which can be used in industrial fermentation processes, in from of polysaccharides (cellulose, hemicellulose). Wheat straw, one representative of lignocellulosic materials, is sustainably and abundantly available, especially in Europe and North America. However, wheat straw, just like any other lignocellulosic material, needs to be pretreated in one way or the other in order to generate sufficient quantities of monosaccharides. One widely used pretreatment for lignocellulosic material is steam explosion combined with enzymatic hydrolysis. In this study, the effects of steam exploding wheat straw in combination with water are presented. By impregnation with water, saccharide yields from subsequent enzymatic hydrolysis increased from 18.8 to $22.6 \mathrm{~g} \mathrm{~L}^{-1}$ for glucose and 13.8 to $16.4 \mathrm{~g} \mathrm{~L}^{-1}$ for xylose, respectively. Moreover, the basic steam explosion parameters residence time and temperature were optimized in ranges from 5 to $20 \mathrm{~min}$ and $180-200^{\circ} \mathrm{C}$. This further optimization increased the maximum saccharide yield to $41.2 \mathrm{~g} \mathrm{~L}^{-1}$ for glucose $\left(200^{\circ} \mathrm{C}, 15 \mathrm{~min}\right)$ and $18.9 \mathrm{~g} \mathrm{~L}^{-1}$ for xylose $\left(190{ }^{\circ} \mathrm{C}, 10 \mathrm{~min}\right)$. Finally, the growth of the intensively investigated biotechnological production host Yarrowia lipolytica on hydrolysates derived from different steam explosion parameters was evaluated. Y. lipolytica grew well in media containing up to $90 \%$ wheat straw hydrolysate as sole carbon source, demonstrating the potential as substrate for biotechnological processes.
\end{abstract}

Keywords Steam explosion $\cdot$ Lignocellulose $\cdot$ Wheat straw $\cdot$ Impregnation $\cdot$ Bioconversion $\cdot$ Yarrowia lipolytica

\section{Introduction}

Our society observes a growing demand for chemicals produced from sustainable sources. Such bio-chemicals can for example be produced chemically or biotechnologically from lignocellulosic waste- or by-products of agro-industrial processes [1]. One approach for converting lignocellulosic biomass is by fermentation with microorganisms, reviewed in [2]. However, microbial decomposition of the recalcitrant lignocellulosic material is a rather slow process and only a minority of microorganisms are able to degrade lignocellulosic structures, especially certain fungi [3-5]. Therefore, many current

Alexander Zwirzitz

alexander.zwirzitz@fh-wels.at

1 University of Applied Sciences Upper Austria, Stelzhamerstraße 23, 4600 Wels, Austria

2 Ludwig Boltzmann Institute for Rare and Undiagnosed Diseases, Lazarettgasse 14, 1090 Vienna, Austria biotechnological processes in which lignocellulosic biomass is fermented rely on pretreatment procedures that disrupt the raw material's structure. Once the structure composed of lignin, cellulose, and hemicellulose is disintegrated, it can be saccharified by purified enzymes or microorganisms themselves [6,7]. Various mechanical (milling, extrusion, or ultrasonication), chemical (acidic, alkaline, or organic solvents), and physico-chemical (liquid hot water extraction and ammonia fiber explosion) pretreatment methods that disrupt lignocellulosic structures have been developed, reviewed in $[8,9]$. Another widely used hydrothermal method is steam explosion. In this process, the raw material is subjected to steam for a certain time under a certain pressure, followed by an explosive decompression. As a consequence, the recalcitrant micro-structure of the fibers is disrupted, and is therefore more accessible for subsequent processes, e.g., enzymatic hydrolysis, which releases fermentable sugars $[10,11]$. Clearly, the key process parameters pressure, residence time, and temperature have a significant impact on the outcome of the whole procedure and, hence, all subsequent processes 
[12]. To find out optimal combinations of these factors for various types of raw material, a myriad of experiments would be necessary. To reduce the number of required experiments, statistical design of experiment approaches has been employed [13]. Furthermore, the inter-dependence of these factors has been described by the severity factor $\left(R_{0}\right)$, which is often used to estimate the intensity of the steam explosion treatment a priori [14]. The outcome of the process can be predicted by the general rule: the higher the severity factor, the more disrupted the structure of the steam-exploded material. Hence, the more efficient the subsequent enzymatic hydrolysis and saccharide yield [10]. Next to polysaccharides, substances that can inhibit microbial growth, like furfural, hydroxymethylfurfural (HMF), acetic acid, and formic acid, are also created by steam exploding lignocellulosic material. Higher severity factor treatments favor the generation of such substances [15]. Besides adjustment of process parameters, chemical pretreatments of the raw material before steam explosion, such as acid [16-18] or alkaline [19, 20] impregnation, have been described to be successful techniques that increase subsequent enzymatic saccharification.

In Europe, wheat straw is an abundantly and sustainably available raw material [21, 22]. As with other lignocellulosic biomass, efficient pretreatment and conversion strategies are required to efficiently generate fermentable carbohydrates from wheat straw $[23,24]$. According to literature, wheat straw contains between $30.4-41.7 \mathrm{~g}$ cellulose and 21.3$32.8 \mathrm{~g}$ hemicellulose per $100 \mathrm{~g}$. The amount of monomeric saccharides generated from that ranges up to $38.8 \mathrm{~g}$ glucose and between 13.4 and $22.8 \mathrm{~g}$ xylose, depending on the pretreatment [25-29]. Few studies have been performed on steam explosion parameters of wheat straw in order to improve subsequent saccharification by enzymatic hydrolysis [28, 29]. Further studies found that pretreatment with acid $[30,31]$ or impregnation with water, which was then removed before steam explosion [32], increased saccharide content after subsequent enzymatic hydrolysis. However, only limited amount of data are available that actually assessed the growth of biotechnologically relevant microorganisms (other than Saccharomyces cerevisiae) on wheat straw hydrolysates in respect to steam explosion parameters.

In the present work, we investigated the effect of impregnating wheat straw with water directly in the reaction chamber of the steam explosion device, and describe the optimization of the parameters temperature and residence time for this approach. The hydrolysates generated by this method display increased sugar concentrations, while inhibitor concentrations remained low. In order to evaluate the suitability of these hydrolysates as carbon sources in biotechnological processes, we analyzed growth of the non-conventional yeast Yarrowia lipolytica, which has widely been used as a production host in biotechnological studies over the last few years $[33,34]$.

\section{Materials and methods}

\subsection{Raw material}

Wheat straw was obtained from local farmers in Upper Austria. It had a relative moisture content of $6.6 \%$. Before steam explosion, straw was chopped to a particle size of 2-3 $\mathrm{cm}$ with an electrical garden shredder (GE260, Viking, Kufstein, Austria). The dry weight of the wheat straw was determined using an IR moisture analyzer (Ohaus MB45).

\subsection{Steam explosion}

Steam explosion was performed, as previously described [35], in a lab scale reactor (VAM GmbH \& Co KG, Linz, Austria). Briefly, $450 \mathrm{~g}$ of dried and chopped wheat straw (6.6\% moisture content) was mixed with $\mathrm{dH}_{2} \mathrm{O}$ at the indicated ratios, and steam explosion was performed at indicated residence time and temperature conditions at $1.5 \mathrm{MPa}$. When ratios and conditions are not specifically stated, we used a 1:1 mixture with $\mathrm{dH}_{2} \mathrm{O}$ and $200{ }^{\circ} \mathrm{C}$ for $10 \mathrm{~min}$ at $1.5 \mathrm{MPa}$. Subsequently, the moisture content of steam-exploded wheat straw was determined using an IR moisture analyzer (Ohaus MB45). In experiments with varying water ratios, dried wheat straw was mixed with $\mathrm{dH}_{2} \mathrm{O}$ in ratios $1: 1$ and 2:1, and steam-exploded at $180{ }^{\circ} \mathrm{C}$ for $20 \mathrm{~min}$ at $1.5 \mathrm{MPa}$. The varying time and temperature values of parameter optimization experiments are presented in Table 1.

\subsection{Enzymatic hydrolysis}

For experiments in which steam-exploded wheat straw was dried before hydrolysis, it was placed for 7 days at $40^{\circ} \mathrm{C}$ in a drying chamber (Binder FD115, Tuttlingen, Germany). In all other experiments, steam-exploded wheat straw was hydrolyzed immediately after steam explosion. Steam-exploded wheat straw was hydrolyzed at $10 \%$ solids loading. Briefly, wheat straw was mixed in a 1:10 (dryweight:buffer) ratio in $0.1 \mathrm{M}$ citric acid buffer and the $\mathrm{pH}$ was adjusted to 5.0. Then, $0.3 \mathrm{ml}$ Accellerase 1500 (Genencor) per gram dry weight of wheat straw was added. After incubation at $50{ }^{\circ} \mathrm{C}$ and shaking at $120 \mathrm{rpm}$ for $72 \mathrm{~h}$, larger particles were removed by filtration in two subsequent steps using $7-12 \mu \mathrm{m}$ and $2-4 \mu \mathrm{m}$ filters. The liquid hydrolysate was sterile-filtered and stored at $4{ }^{\circ} \mathrm{C}$.

\subsection{Electron microscopy}

To compare the morphological structure of the straw upon pretreatment with different steam explosion parameters, samples were taken directly after steam explosion. Samples were mounted to the pin holder with an electrically conductive double-sided tape and gold-coated with a sputter coater (Cressington 108, Tescan, Dortmund, Germany) for $20 \mathrm{~s}$. 
Table 1 Overview of applied steam explosion parameters

\begin{tabular}{llllll}
\hline Parameter no. & Severity factor* & Temperature $\left({ }^{\circ} \mathrm{C}\right)$ & Time $(\mathrm{min})$ & Wheat straw $(\mathrm{g})$ & Water $(\mathrm{ml})$ \\
\hline P1 & 3,66 & 180 & 20 & 500 & 500 \\
P2 & 3,64 & 190 & 10 & 500 & 500 \\
P3 & 3,64 & 200 & 5 & 500 & 500 \\
P4 & 3,94 & 200 & 10 & 500 & 500 \\
P5 & 4,12 & 200 & 15 & 500 & 500 \\
\hline
\end{tabular}

*severity factor calculated according to [14]
Images were acquired with a scanning electron microscope (VEGA 2 LMU, Tescan, Dortmund Germany) with a secondary electron detector at $10.00 \mathrm{kV}$.

\subsection{Sugar and inhibitor quantification by HPLC}

To analyze saccharides and inhibitory compounds, the sterilefiltered hydrolysate samples were centrifuged and the supernatant was used for the quantification by HPLC, using a Jasco HPLC 2000 plus series (Biolab, Vienna, Austria) with an Aminex HPX $87 \mathrm{H}$ column at $65{ }^{\circ} \mathrm{C} . \mathrm{H}_{2} \mathrm{SO}_{4}(c=5 \mathrm{mmol}$ $1^{-1}$ ) was used as eluent at an isocratic flow rate of $0.8 \mathrm{ml}$ $\min ^{-1}$. Sugars were detected with a refractive index and organic acids and inhibitors by a UV detector. Data were analyzed with ChromPass (Version 1.8.6.1, Jasco Europe, Italy). For the preparation of standards, chemicals were obtained from the following suppliers: xylitol from Sigma-Aldrich (Steinheim, Germany), glucose, xylose, arabinose, acetic acid and formic acid from Carl Roth (Karlsruhe, Germany), cellulose form Machery-Nagel (Düren, Germany), furfural from Merck (Hohenbrunn, Germany), and hydroxymethylfurfural (HMF) from Alfa Aesar (Kandel, Germany). Resulting saccharide yields $(\mathrm{g})$ per $100 \mathrm{~g}$ wheat straw were calculated as following:

[g] saccharide per $100 \mathrm{~g}$ wheat straw

[g] saccharide per L as measured by HPLC $* 100$

[\%] dry mass of wheat straw*[g] wheat straw loading per $\mathrm{L}$

\subsection{Strains and culture conditions}

The Y. lipolytica strain W29 used in this study was gratefully supplied by Dr. Klaus Natter, University of Graz, Austria. The strains were maintained on YPDagar (yeast extract $10 \mathrm{~g} \mathrm{l}^{-1}$; peptone from casein $20 \mathrm{~g}$ $1^{-1}$; glucose $20 \mathrm{~g} \mathrm{l}^{-1}$; agar $20 \mathrm{~g} \mathrm{l}^{-1}$ all from Carl Roth, Karlsruhe, Germany). Liquid cultures were prepared in either YP (yeast extract $10 \mathrm{~g}^{-1}$; peptone from casein $20 \mathrm{~g}^{-1}$ ), YNB (yeast nitrogen base without amino acids $6.7 \mathrm{~g}^{-1}$ from Carl Roth, Karlsruhe, Germany) with glucose $20 \mathrm{~g}^{-1}$ from Carl Roth, Karlsruhe, Germany (YPD, YNBD), or hydrolysate (YPH,
YNBDH, YNBH) as carbon source. YPH media were prepared by adding the indicated amounts of sterilefiltered wheat straw hydrolysate to $1.5 \mathrm{~g} \mathrm{~L}^{-1}$ yeast extract, $3 \mathrm{~g} \mathrm{~L}^{-1}$ Peptone, $2 \mathrm{~g} \mathrm{~L}^{-1}$ potassium dihydrogen phosphate (Carl Roth, Karlsruhe, Germany), $1 \mathrm{~g} \mathrm{~L}^{-1}$ ammonium sulfate (VWR Chemicals, Fontenay, France), and $0.5 \mathrm{~g} \mathrm{~L}^{-1}$ magnesium sulfate heptahydrate (Carl Roth, Karlsruhe, Germany). YNBH medium was prepared by adding sterile-filtered wheat straw hydrolysate to $10 \times$ YNB stock solutions and diluting with $\mathrm{dH}_{2} \mathrm{O}$ to yield indicated $\%(\mathrm{v} / \mathrm{v})$ of wheat straw hydrolysate and a final YNB concentration of $6.7 \mathrm{~g} \mathrm{~L}^{-1}$. For example, YNBH20 means $20 \%$ of $\mathrm{dH}_{2} \mathrm{O}$ were replaced with hydrolysate. Liquid cultures were incubated at 28 ${ }^{\circ} \mathrm{C}$ and $170 \mathrm{rpm}$ in an orbital shaker. Yeast growth was evaluated by optical density measurements with a photometer (Dr. Lange ION 500) at $600 \mathrm{~nm}$. Yeast yield was analyzed by centrifugation of $10 \mathrm{ml}$ of stationary phase $(72 \mathrm{~h})$ culture and determination of dry cell weight (DCW) of the pellet, which was resuspended in $1 \mathrm{ml}$ on an IR moisture analyzer (Ohaus MB15). The resulting yeast yield (g) per $100 \mathrm{~g}$ wheat straw was calculated as following:

[g] yeast as measured from $10 \mathrm{ml}$ culture $* 100 * 100$

[\%]wheat straw hydrolysate in media*[\%] dry mass of wheat straw*[g] wheat straw loading per $\mathrm{L}$

\subsection{Statistical analysis, modelling, and optimization}

All experiments were performed at least three times, each time in triplicates. Statistical analysis was performed with Prism v8.0.2 - GraphPad Software, San Diego, CA, USA. Outliers were detected by a Grubbs outlier test and statistical significance was calculated via one-way ANOVA followed by Fisher's LSD test. Values are displayed as means with standard deviation of the mean, $p<0.01=*, p<0.05=* *$, and $p$ $<0.005=* * *$. Modelling, fitting, and optimization was based on a circumscribed central composite design and was performed using a response surface methodology approach in Design-Expert 12.0.12.0 (Stat-Ease Inc., Minneapolis, USA). Optimization of the parameters temperature and residence time was performed for maximal saccharide yield, while minimizing inhibitor yield. 


\section{Results}

In order to broaden the knowledge on steam explosion of wheat straw and its further use in biotechnological processes, we employed an approach of soaking dried wheat straw with $\mathrm{dH}_{2} \mathrm{O}$ directly before steam explosion in the reaction vessel, without removing excess water. Then, we analyzed the influence on subsequent enzymatic hydrolysis, on the release of free saccharides and inhibitors, and ultimately on growth of the non-conventional model oleaginous yeast $Y$. lipolytica.

\subsection{Effect of combining wheat straw with $\mathrm{dH}_{2} \mathrm{O}$ for steam explosion}

First, we examined the influence of the presence of various ratios of $\mathrm{dH}_{2} \mathrm{O}$ while steam exploding wheat straw. We performed steam explosion experiments $\left(180^{\circ} \mathrm{C}, 20 \mathrm{~min}\right)$ with dried wheat straw without adding $\mathrm{dH}_{2} \mathrm{O}$, and with dried wheat straw mixed with $\mathrm{dH}_{2} \mathrm{O}$ in the ratios of $1: 1$ and $2: 1$. Subsequently, the resulting polysaccharides were enzymatically hydrolyzed to monosaccharides, which were analyzed by HPLC.

Steam explosion of dried wheat straw, with a relative moisture content (see Supplemental Fig. S1) of $6.6 \pm 0.1 \%$, yielded $18.8 \pm 1.3 \mathrm{~g} \mathrm{~L}^{-1}$ glucose and $13.8 \pm 1.9 \mathrm{~g} \mathrm{~L}^{-1}$ xylose; see Fig. 1a. Combining dried wheat straw with $\mathrm{dH}_{2} \mathrm{O}$ in a ratio of $2: 1$ slightly increased the amount of glucose $20.0 \pm 1.7 \mathrm{~g} \mathrm{~L}^{-1}$, while the amount of xylose was not significantly changed $13.3 \pm 2.0 \mathrm{~g} \mathrm{~L}^{-1}$. When combining wheat straw with $\mathrm{dH}_{2} \mathrm{O}$ in a ratio of $1: 1$, the values of monosaccharides were again significantly increased. In this setting, the highest levels of both glucose $\left(22.6 \pm 0.4 \mathrm{~g} \mathrm{~L}^{-1}\right)$ and xylose $(16.4 \pm 1.0 \mathrm{~g}$ $\mathrm{L}^{-1}$ ) were detected after enzymatic hydrolysis.

Besides saccharides, also compounds that can inhibit microbial growth are released by steam explosion of lignocellulosic biomass. Therefore, we also analyzed the presence of the

Fig. 1 Effect of combination of wheat straw with various $\mathrm{dH} 2 \mathrm{O}$ ratios in steam for explosion on saccharide and inhibitors concentrations. HPLC analysis of a saccharides and $\mathbf{b}$ inhibitors in hydrolysates generated by steam explosion of wheat straw without additional $\mathrm{dH}_{2} \mathrm{O}$, or mixed with $\mathrm{dH}_{2} \mathrm{O}$ in ratios of $1: 1$ or $2: 1$ Displayed are mean values $\pm \mathrm{SD}$ $(n=2)$ in $\mathrm{g} \mathrm{L}^{-1}$ a)

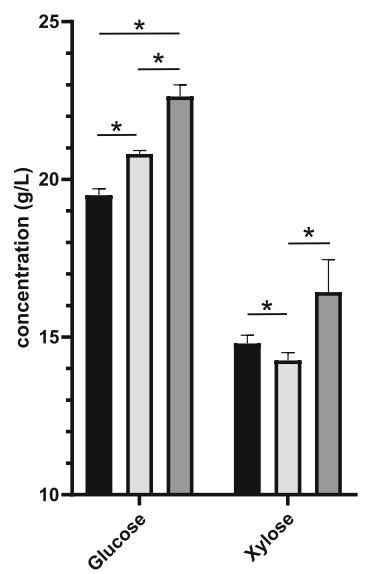

most common growth inhibitors, acetic acid, formic acid, furfural, and HMF. Steam explosion of dried wheat straw without mixing with $\mathrm{dH}_{2} \mathrm{O}$ yielded $3.1 \pm 0.7 \mathrm{~g} \mathrm{~L}^{-1}$ acetic acid, 2.1 $\pm 0.2 \mathrm{~g} \mathrm{~L}^{-1}$ formic acid, $145.0 \pm 6.0 \mathrm{mg} \mathrm{L}^{-1}$ furfural, and 223.0 $\pm 210.0 \mathrm{mg} \mathrm{L}^{-1}$ 5-HMF; see Fig. 1b. Combining dried wheat straw with $\mathrm{dH}_{2} \mathrm{O}$ in a ratio of $2: 1$ yielded $3.0 \pm 0.5 \mathrm{~g} \mathrm{~L}^{-1}$ acetic acid, $1.8 \pm 0.3 \mathrm{~g} \mathrm{~L}^{-1}$ formic acid, $144.0 \pm 5.0 \mathrm{mg} \mathrm{L}^{-1}$ furfural, and $25.0 \pm 2.0 \mathrm{mg} \mathrm{L}^{-1} 5$-HMF. The values for inhibitors when combining wheat straw with $\mathrm{dH}_{2} \mathrm{O}$ in a ratio of $1: 1$ were as follows: $3.2 \pm 0.2 \mathrm{~g} \mathrm{~L}^{-1}$ acetic acid, $2.3 \pm 0.1 \mathrm{~g} \mathrm{~L}^{-1}$ formic acid, $100.0 \pm 23.0 \mathrm{mg} \mathrm{L}^{-1}$ furfural, and $30.0 \pm 3.0 \mathrm{mg} \mathrm{L}^{-1} 5$ HMF, detected after enzymatic hydrolysis. Regarding the inhibitory compounds, statistically significant differences could only be detected for formic acid, which was slightly but significantly lower at a 2:1 ratio of straw to $\mathrm{dH}_{2} \mathrm{O}$, and furfural, which was significantly lower at a ratio of 1:1 compared to the other ratios.

\subsection{Effect of drying wheat straw before enzymatic hydrolysis}

We investigated the effect of thermally drying steamexploded wheat straw before hydrolysis on saccharide and inhibitor yields Since a wheat straw to $\mathrm{dH}_{2} \mathrm{O}$ ratio of $1: 1$ led to the highest amounts of monosaccharides, the following experiments were performed under these conditions. When hydrolysis was performed after drying the steam-exploded wheat straw for 7 days, significantly less glucose $(20.8 \pm$ $1.7 \mathrm{~g} \mathrm{~L}^{-1}$ vs. $\left.24.0 \pm 3.2 \mathrm{~g} \mathrm{~L}^{-1}\right)$ and slightly less xylose (13.6 $\pm 2.8 \mathrm{~g} \mathrm{~L}^{-1}$ vs. $15.3 \pm 2.7 \mathrm{~g} \mathrm{~L}^{-1}$ ) were detected as compared to hydrolyzing directly after steam explosion; see Fig. 2 a. However, after 7 days drying, also significantly less acetic acid $\left(1.7 \pm 0.2 \mathrm{~g} \mathrm{~L}^{-1}\right.$ vs. $\left.3.2 \pm 0.2 \mathrm{~g} \mathrm{~L}^{-1}\right)$ was detected. Before drying, $92.0 \pm 27.0 \mathrm{mg} \mathrm{L}^{-1}$ furfural and vs. $28.0 \pm$ $3.0 \mathrm{mg} \mathrm{L}^{-1}$ HMF was detected, while after drying these two substances could not be detected at all; see Fig. 2b. Since the

b)

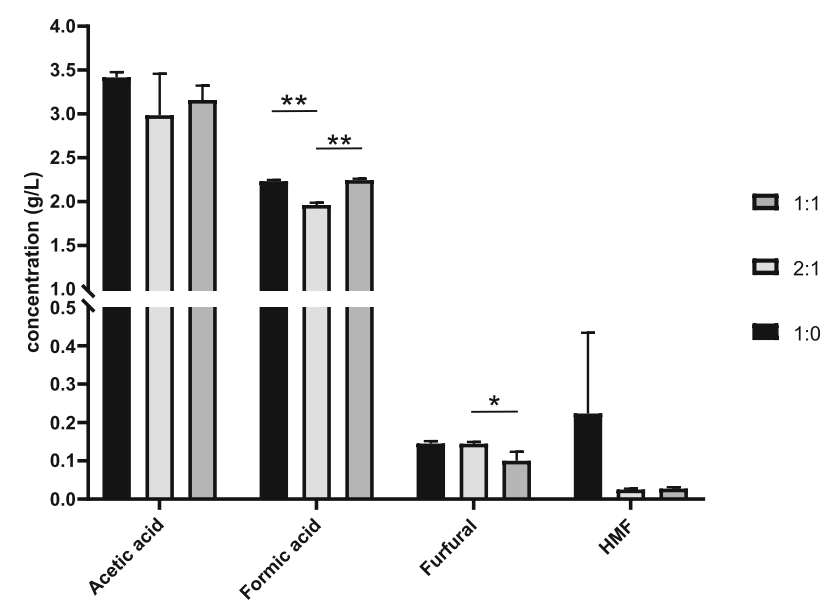


Fig. 2 Effect of drying of wheat straw steam before enzymatic hydrolysis on saccharide and inhibitors. HPLC analysis of a saccharides and $\mathbf{b}$ inhibitors in hydrolysates generated directly after steam explosion or after 7 days drying of steam-exploded wheat straw. Displayed are mean values $\pm \mathrm{SD}(n=5)$ in $\mathrm{g} \mathrm{L}^{-1}$ a)

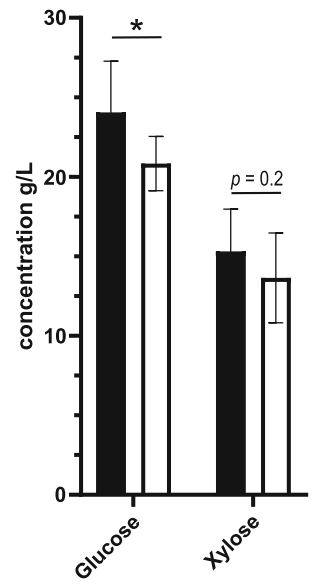

b)

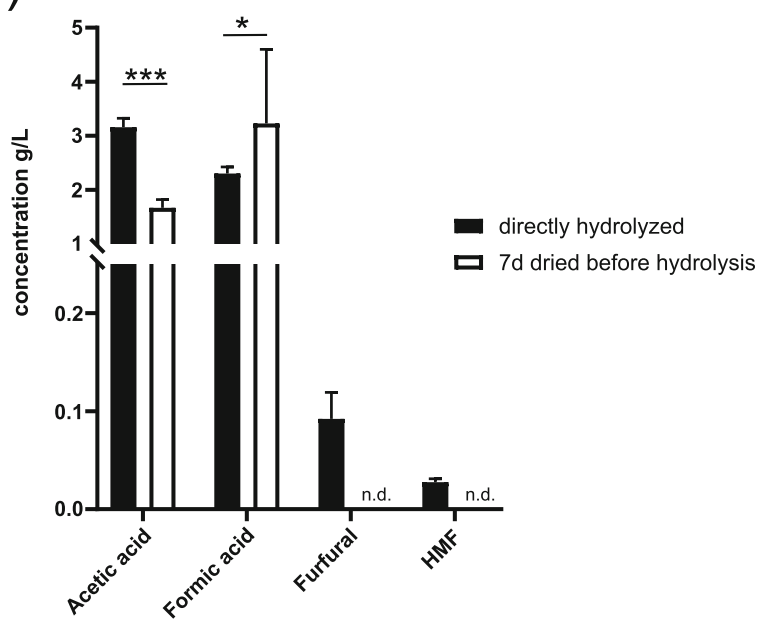

amount of fermentable monosaccharides was highest when steam-exploded with a wheat straw to $\mathrm{dH}_{2} \mathrm{O}$ ratio of $1: 1$ and direct enzymatic treatment after steam explosion, all subsequent experiments were performed under these conditions.

\subsection{Optimization of time and temperature parameters for steam explosion of wheat straw}

After optimizing $\mathrm{dH}_{2} \mathrm{O}$ and drying parameters, we continued with the adaptation of the two basic steam explosion parameters, temperature and residence time. It has previously been demonstrated that steam explosion of overnight impregnated wheat straw was most effective at $200{ }^{\circ} \mathrm{C}$ with a residence time of $10 \mathrm{~min}$ [32]. This corresponded to a severity factor of 3.64, calculated according to [14]. For our approach with mixing wheat straw and $\mathrm{dH}_{2} \mathrm{O}$ directly in the reaction vessel, we also applied lower and higher severity factors, corresponding to lower temperatures and different residence times. For an overview of the applied parameters, see Table 1. As can be seen in Supplemental Fig. S1, the relative moisture content of wheat straw after steam explosion with the various parameters was $81.1 \pm 2.0 \%$ for $\mathrm{P} 1,78.2 \pm 1.4 \%$ for $\mathrm{P} 2,77.1 \pm 2.2 \%$ for $\mathrm{P} 3,78.6 \pm 1.5 \%$ for $\mathrm{P} 4$, and $77.7 \pm 1.5 \%$ for $\mathrm{P} 5$.

We analyzed monosaccharides present in hydrolysates generated from wheat straw steam-exploded at indicated parameters and a water ratio of 1:1. Figure $3 a$ shows that higher severity factors P4 and P5 yielded significantly higher levels of glucose $\left(36.0 \pm 5.8 \mathrm{~g} \mathrm{~L}^{-1}\right.$ and $41.2 \pm 9.6 \mathrm{~g} \mathrm{~L}^{-1}$, respectively) than the lower severity factor treatments P1, P2, and P3 $(26.5 \pm 2.6 \mathrm{~g}$ $\mathrm{L}^{-1}, 25.8 \pm 1.2 \mathrm{~g} \mathrm{~L}^{-1}$, and $30.6 \pm 7.3 \mathrm{~g} \mathrm{~L}^{-1}$, respectively). The parameter $\mathrm{P} 3$ also yielded significantly higher quantities of glucose than $\mathrm{P} 1$ and $\mathrm{P} 2$. Concerning xylose, the $180{ }^{\circ} \mathrm{C}$ parameter $\mathrm{P} 1\left(15.8 \pm 1.1 \mathrm{~g} \mathrm{~L}^{-1}\right)$ resulted in significantly lower amounts than parameters $\mathrm{P} 2$ and $\mathrm{P} 3\left(18.9 \pm 0.3 \mathrm{~g} \mathrm{~L}^{-1}\right.$ and $17.7 \pm 3.3 \mathrm{~g}$ $\mathrm{L}^{-1}$, respectively), although all share the same severity factor $R_{0}$. The higher $R_{0}$ parameter $\mathrm{P} 4$ resulted in slightly less xylose $\left(15.5 \pm 2.7 \mathrm{~g} \mathrm{~L}^{-1}\right)$, although not significantly different from $\mathrm{P} 2$ and P3. The highest $R_{0}$ parameter P5 $\left(11.3 \pm 1.4 \mathrm{~g} \mathrm{~L}^{-1}\right)$ yielded significantly less xylose than P2, P3, and P4.

In line with our previous analyses, we also analyzed the amounts of growth inhibitory compounds for these parameters. Here, we could not detect statistically significant differences due to large standard deviations. However, as can be seen in Fig. 3b, the trend shows that especially for acetic acid, but also furfural and HMF, the higher the severity factor, the more inhibitors are produced. Concerning formic acid, although P3 yields the lowest value $\left(0.5 \pm 0.4 \mathrm{~g} \mathrm{~L}^{-1}\right)$, no clear trend regarding the severity factor can be observed. The only statistically significant difference is between P2 vs. P4 (1.5 \pm $0.03 \mathrm{~g} \mathrm{~L}^{-1}$ vs. $\left.1.6 \pm 0.03 \mathrm{~g} \mathrm{~L}^{-1}\right)$. To get a more detailed insight on the effects of the different severity factors on the microscopic structure of the raw material, wheat straw steamexploded with the parameters differing in severity factor (P3, P4, and P5) was analyzed by electron microscopy. As can be seen in Supplemental Fig. S2, the microscopic structure of the straw was efficiently disrupted by the steam explosion treatment. Especially, the higher severity factor parameters effectively ruptured the fibers of the straw.

Based on these data, the optimal parameter combinations (residence time and temperature) for maximizing saccharide yields while minimizing inhibitor yields were modelled. The model was based on a circumscribed central composite experimental design (shown in Table S3) to which a response surface methodology (RSM) was applied. The effects of temperature and residence time on saccharide yields were described by a quadratic function $(p<0.0001$ for glucose and $p=0.02$ for xylose). Acetic acid $(p=0.08)$ and formic acid $(p=0.23)$ were described by a 2 -factor interaction function. The corresponding 3-D response surface plots are shown in Fig. 4a. Based on the desirability function, the optimal parameters were found to be a combination of $200{ }^{\circ} \mathrm{C}$ and 9.2-min residence time. The corresponding desirability plot is depicted in Fig. 4b. 
Fig. 3 HPLC analysis of wheat straw hydrolysate. Amounts of a sugars and $\mathbf{b}$ inhibitors in hydrolysates generated by $72 \mathrm{~h}$ enzymatic hydrolysis of steam explosion of wheat straw with parameters P1-P5. Displayed are mean values $\pm \mathrm{SD}(n=3)$ in $\mathrm{g} \mathrm{L}^{-1}$. ${ }^{\#}$ Statistical significance for glucose in $\mathbf{a}: p<0.001$ for all mean values, except where n.s. is stated a)

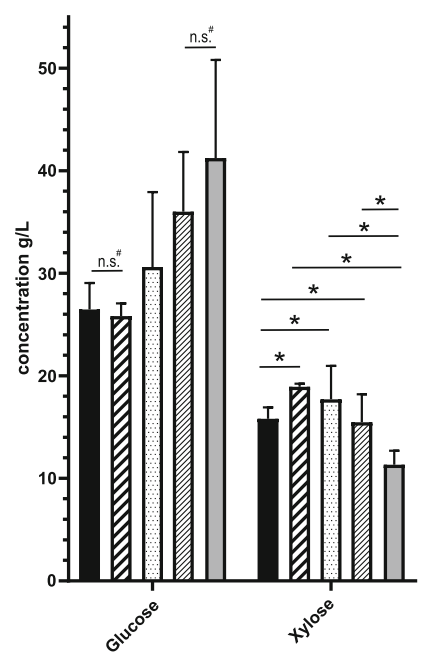

b)

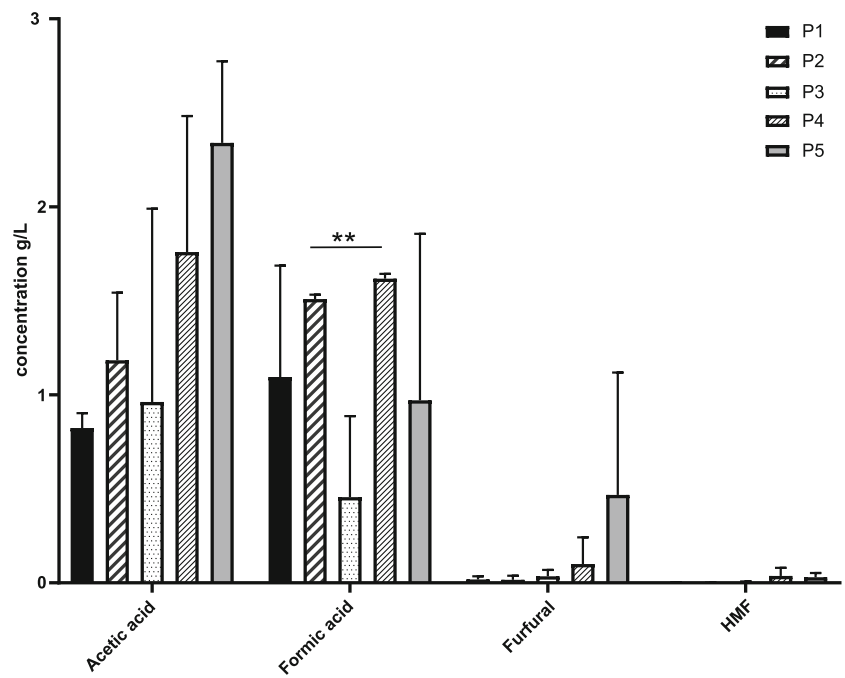

\subsection{Evaluation of wheat straw hydrolysate as carbon source in yeast growth media}

Taken together, we observed a clear correlation of steam explosion severity factor with the amount of monosaccharides generated by subsequent hydrolysis and at least to some extent also inhibitors. In order to investigate the influence of the pretreatment parameters on the suitability of the subsequently generated hydrolysates as component of growth media, the growth of the yeast $Y$. lipolytica in liquid cultures containing steam-exploded wheat straw hydrolysate was evaluated. For these growth evaluation experiments, only hydrolysates generated from parameters P1 to P4 were used, because of the low amount of xylose and higher levels of inhibitory compounds a)
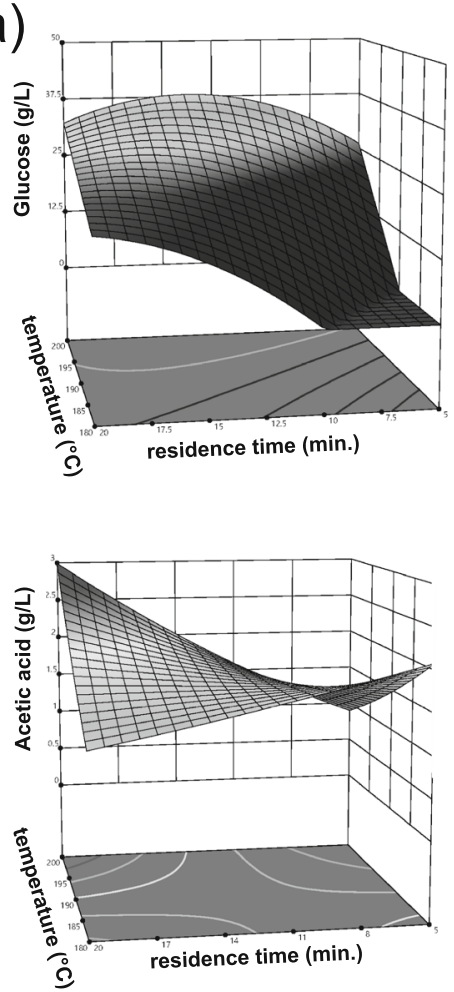

Fig. 4 Optimization of steam explosion parameters. a 3-D response surface methodology plots, based on modelling of the central composite design via quadratic (glucose and xylose) and 2-factor interaction
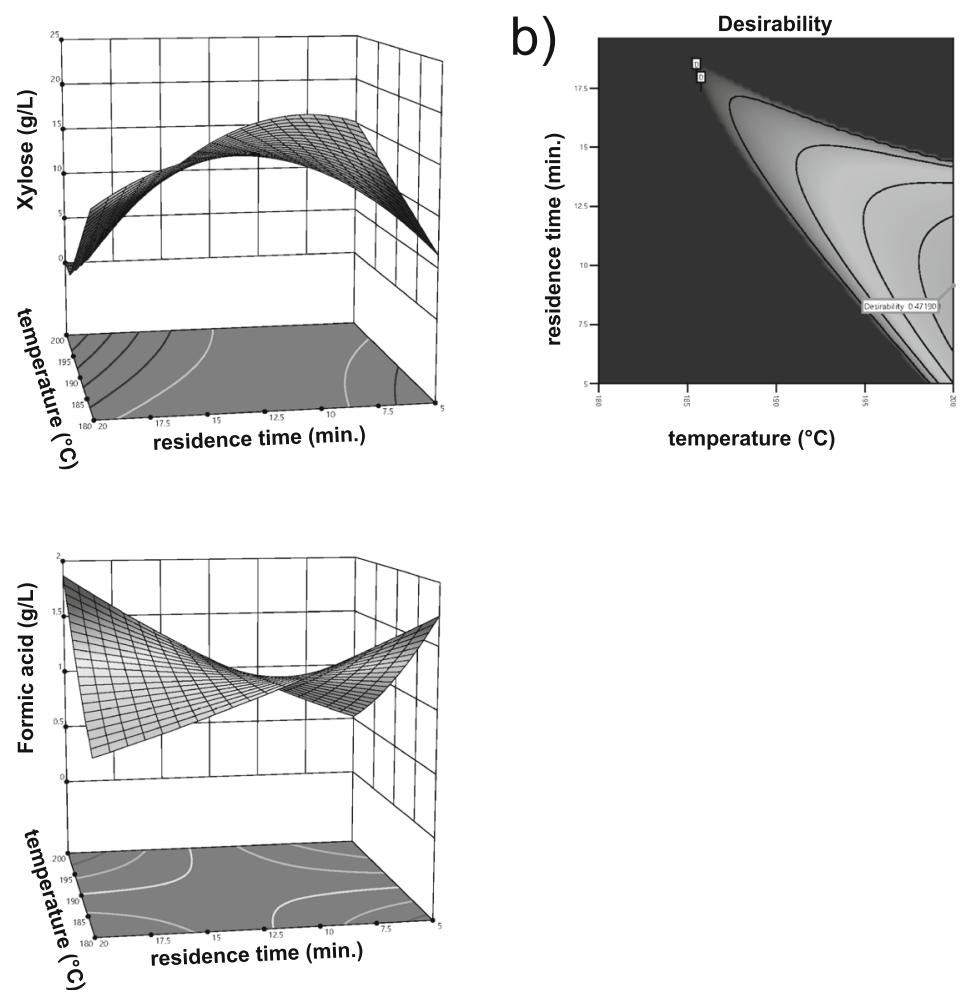

functions (acetic acid and formic acid); $\mathbf{b}$ desirability plot based on optimization of the central composite design's space for maximized saccharide and minimized inhibitor yields 
in P5. When $20 \%$ hydrolysate of either P1, P2, P3, or P4 were used as sole carbon source in yeast media (YPGH), Y. lipolytica grew to the highest $\mathrm{OD}_{600}$ (14 and 13) with hydrolysates generated from wheat straw that was steam-exploded using parameters P3 and P4, as shown in Fig. 5a.

To get a better insight on the effect of hydrolysates on growth of $Y$. lipolytica, we prepared growth media consisting
Fig. 5 Evaluation of wheat straw hydrolysate as yeast growth media. Liquid cultures of

$Y$. lipolytica were grown $\mathbf{a}$ in $\mathrm{YP}$ media containing $20 \%$

hydrolysate (YPH20) derived from steam explosions with conditions $\mathrm{P} 1, \mathrm{P} 2, \mathrm{P} 3$, or $\mathrm{P} 4, \mathbf{b}$ in YPD medium which contains $20 \mathrm{~g} \mathrm{~L}^{-1}$ glucose as carbon source, or YNBDH media which additionally contain varying concentrations $(20-50 \%)$ of hydrolysate (YNBDH20-YNBDH50), and $\mathbf{c}$ in YNB media containing varying concentrations (20-90\%) of hydrolysate (YNBH20-

YNBH90), as sole carbon source. Displayed are mean values $\pm \mathrm{SD}$ $(n=3)$ of optical density $\left(\mathrm{OD}_{600}\right)$ at the indicated time points a)

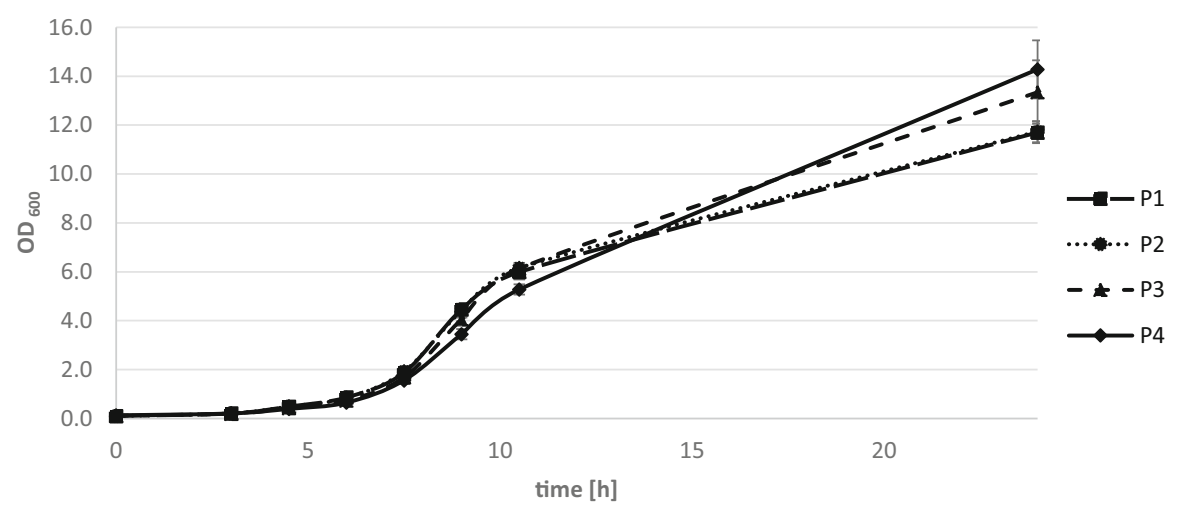

b)

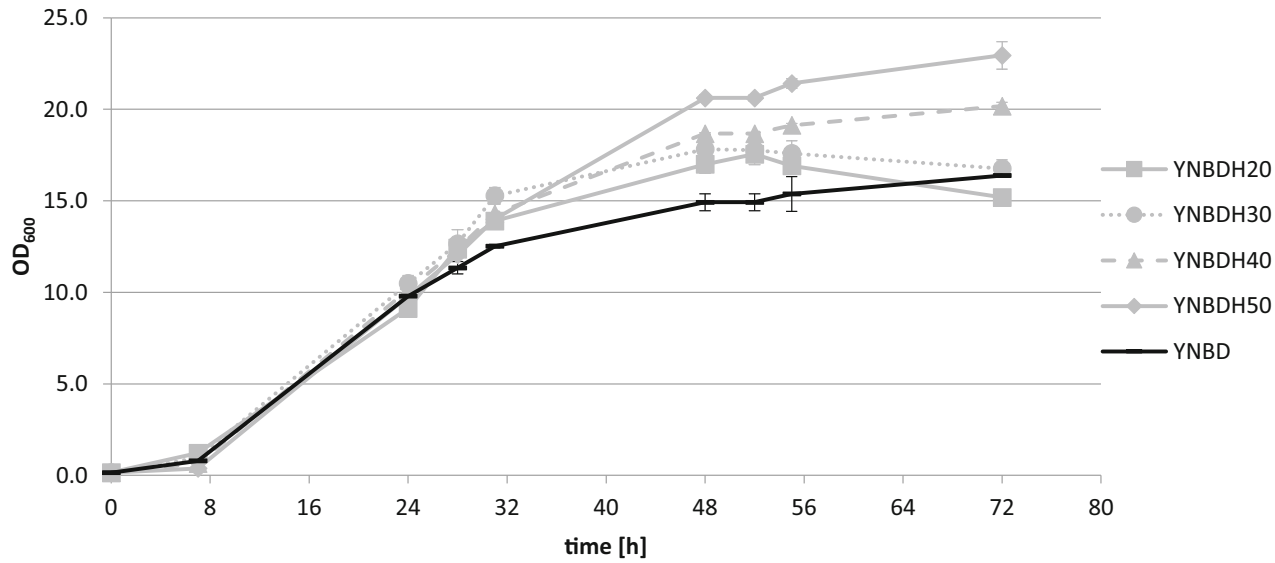

c)

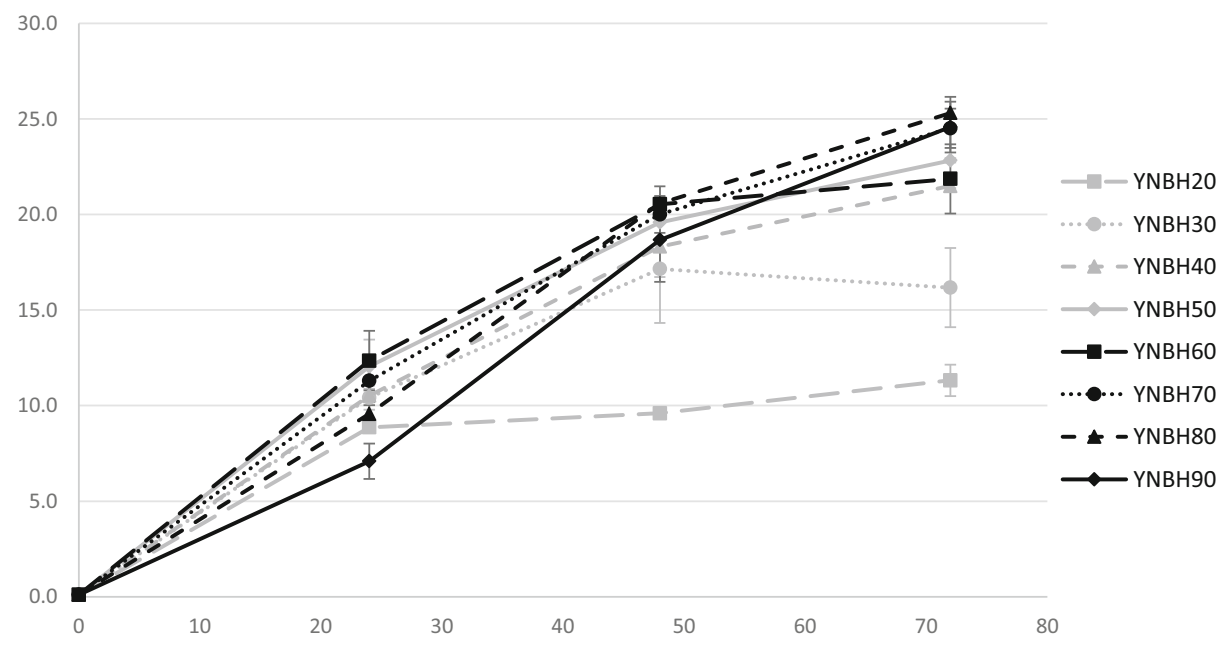


of minimal medium (YNB) with $20 \mathrm{~g} \mathrm{~L}^{-1}$ glucose as carbon source, and added various concentrations of hydrolysate (20$50 \%$ ), generated with parameter P4. Addition of hydrolysate to minimal media containing glucose (YNBD) results in YNBDH media, which enhances growth in a concentration dependent manner, as can be seen in Fig. 5b. The more hydrolysate is added, the better the growth. While addition of $20 \%$ hydrolysate did not significantly affect growth compared to minimal medium ( $\mathrm{OD}_{600}$ of 15 vs. 16 after $72 \mathrm{~h}$ ), addition of $40 \%$ and $50 \%$ hydrolysate resulted in significantly higher growth $\left(\mathrm{OD}_{600}\right.$ of 20 and 22 after $\left.72 \mathrm{~h}\right)$.

Finally, hydrolysates were tested for their ability to substitute glucose as sole carbon source also in minimal media. Additionally, the influence of elevated concentrations of hydrolysate in YNBH media on growth was analyzed. Therefore, hydrolysates generated with parameter P4 were used for the preparation of growth media containing up to 90\% hydrolysate as the sole carbon source. As can be seen in Fig. $5 \mathrm{c}$, the higher the concentration of hydrolysate in the growth media, the higher the $\mathrm{OD}_{600}$ of Y. lipolytica after $72 \mathrm{~h}$. At a hydrolysate concentration of $20 \%$, Y. lipolytica were only able to grow to an $\mathrm{OD}_{600}$ of around 10 , while concentrations of $40 \%$ and $50 \%$ allowed them to grow to $\mathrm{OD}_{600}$ above 20 . The highest optical densities could be reached at hydrolysate concentrations of 70,80 , and $90 \%$. This corresponds to $12.4 \pm$ $0.6 \mathrm{~g}$ yeast dry cell weight per $100 \mathrm{~g}$ wheat straw (initial input for steam explosion) after $72 \mathrm{~h}$ growth in YNBH90.

\section{Discussion}

The study presents strategies for improvement of steam explosion of lignocellulosic raw materials, in particular wheat straw. One general issue with lignocellulosic raw materials is the heterogeneity in the chemical composition of agricultural raw materials in different countries. Thus, the precise values for saccharides and growth inhibitory substances might slightly vary in different publications. Interestingly, the wheat straw we used had the same moisture content (around 6\%, see Supplemental Fig. S1) as compared to previously published values from other European countries. These previous studies impregnated wheat straw in water $(150 \mathrm{~g}$ in $1.5 \mathrm{~L})$ overnight. Then, excess water was removed and the remaining raw material was used for steam explosion. These authors observed higher overall saccharides yields from steam-exploded wheat straw when it was impregnated with water overnight before $[30,32]$. We followed a slightly different and simplified approach, which is impregnation of the raw material with water directly in the reaction chamber of the steam explosion device. As can be seen in Fig. 1, mixing wheat straw with water for steam explosion yielded significantly higher amounts of saccharides after enzymatic hydrolysis (Fig. 1a), while the amounts of inhibitory substances (Fig. 1b) were mostly unchanged or even slightly lower. The absolute quantities of saccharides we obtained from steam explosion with parameter P4 $\left(200{ }^{\circ} \mathrm{C}, 10 \mathrm{~min}\right)$ were slightly higher to those that have previously been reported [32] for overnight impregnation using the same parameters (35.4 vs. $35.8 \mathrm{~g} / 100 \mathrm{~g}$ straw for glucose and $11.7 \mathrm{vs} 15.4 \mathrm{~g} / 100 \mathrm{~g}$ straw for xylose). Due to the higher levels of xylose obtained by our approach, we conclude that especially hemicelluloses were more efficiently hydrolyzed from wheat straw steam-exploded in the presence of $\mathrm{dH}_{2} \mathrm{O}$. Probably the presence of water facilitates autohydrolysis-like processes of hemicelluloses [36] in the early phase of the steam explosion reaction [37-39]. Likewise, when impregnated with water, softwood showed enhanced breakdown upon steam explosion with similar severity factors [40]. The fact that we could not detect significantly higher amounts of inhibitors at higher severity treatments led us to hypothesize that $\mathrm{dH}_{2} \mathrm{O}$ impregnation provides a protective effect. Buffering effects from neutral $\mathrm{pH}$ during steam explosion have been observed previously [41-43].

Lignocellulosic materials can be detoxified from inhibitory substances by several methods, reviewed in [44]. One of them is evaporation. In order to see whether drying of steamexploded wheat straw before hydrolysis has an effect on the amount of saccharides and inhibitory substances, we compared hydrolysates generated from steam-exploded wheat straw that has been dried for 7 days with hydrolysates obtained from straw that has been hydrolyzed directly after steam explosion. Other studies found that drying of lignocellulosic material significantly affected pore size; however, it did not have a substantial effect on saccharide yield after enzymatic hydrolysis [45-47]. When applying our approach, drying the straw resulted in lower amounts of most inhibitors (Fig. 2b), except formic acid, but as well, dried straw yielded less saccharides (Fig. 2a). While we detected slightly less acetic acid, formic acid amounts were even slightly higher in hydrolysates from dried straw. Furfural and HMF were below the levels that have been described to actually have inhibitory effects on yeast [48-51]. Therefore, we concluded that drying straw is not worth the additional time, effort, and energy, at least not when using our approach.

Subsequently, we optimized the steam explosion parameters residence time and temperature for our approach. Because it yielded the highest amount of fermentable sugars, we used wheat straw to $\mathrm{dH}_{2} \mathrm{O}$ ratios of $1: 1$, and directly hydrolyzed after steam explosion for all subsequent experiments. Overall, the higher severity factor parameters yielded higher amounts of glucose (Fig. 3a). Likewise, wheat straw impregnated overnight with $\mathrm{dH}_{2} \mathrm{O}$ yielded more glucose when steam-exploded at higher temperatures, while xylose yields were reduced at higher severity factor treatments. The authors detected the highest quantities of xylose in hydrolysates from wheat straw steam-exploded at $190{ }^{\circ} \mathrm{C}$ for $10 \mathrm{~min}$ [32]. Also, in our experiments, xylose quantities were highest with the parameters 
$190{ }^{\circ} \mathrm{C}$ for $10 \mathrm{~min}(\mathrm{P} 2)$, while the highest severity factor parameter P5 yielded significantly less xylose; see Fig. 3a. Overall, parameter $\mathrm{P} 4\left(200^{\circ} \mathrm{C}, 10 \mathrm{~min}\right)$ resulted in the highest total saccharide yield after enzymatic hydrolysis. This parameter combination has proven to result in the highest glucose yield also for the overnight impregnation approach [32]. Similar relations between steam explosion temperatures and glucose and xylose yields were observed previously [52].

Concerning inhibitory compounds, we found the higher the severity factor treatment, the higher the amount of acetic acid, furfural, and HMF. For formic acid, no clear trend can be observed. However, the lowest value was detected when applying parameter P3; see Fig. 3b. When applying parameter $\mathrm{P} 4$, we detected slightly lower quantities of acetic acid, HMF, and furfural, but slightly higher values for formic acid than reported for overnight impregnation [32]. Obviously, higher severity factor treatments allow the straw to be more efficiently hydrolyzed. This can also be inferred from the modelled 3D RSM plots. As illustrated in Fig. 4a, glucose is more efficiently hydrolyzed from straw that was treated with higher severity factor conditions. With one limitation, glucose yield from $200{ }^{\circ} \mathrm{C}$ treatments diminished when applied for longer than $15 \mathrm{~min}$. Similar to what has been described by the experimental data, xylose showed a less trivial response to treatment severity also in the model. Treatments at temperatures and times at the borders of the design space spectrum (low as well as high severity factors) yielded reduced amounts of xylose than moderate severity factor treatments. The highest amounts of xylose could be generated from short treatments at high temperatures, moderately long residence times at moderate temperatures, or long treatments at lower temperatures (Figs. 3a and 4a). Also, other authors found that xylose could be most efficiently hydrolyzed from water-impregnated wheat straw when steam-exploded at moderate conditions $\left(190^{\circ} \mathrm{C}\right.$, $10 \mathrm{~min}$ ) [32]. Based on the covered design space, RSM did not allow applying a quadratic model to the inhibitors. Consequently, inhibitors were predicted most reliably by a 2 -factor interaction function. Due to rather large variations of the experimental data, the models for the inhibitors were not statistically significant, but still showed a reasonable interpolation of the data (Figs. $3 \mathrm{~b}$ and $4 \mathrm{a}$ ). The optimal combination of parameters $\left(200{ }^{\circ} \mathrm{C}, 9.2 \mathrm{~min}\right)$ was found by the desirability plot (Fig. 4b), and is close to the experimentally applied parameter $\mathrm{P} 4\left(200^{\circ} \mathrm{C}, 10 \mathrm{~min}\right)$, which was also suggested by the optimization calculation with only a slightly smaller desirability value.

A widespread understanding is that higher severity factors disrupt the straws physical integrity more. Consequently, cellulose and hemicellulose might be more easily accessible for enzymatic hydrolysis [10, 31]. This observation can also be inferred from our electron microscopic images of (steamexploded) wheat straw in Supplemental Fig. S2. While untreated wheat straw shows an organized and compact structure, the surface of steam-exploded wheat straw became scattered and porous, due to the destruction of the lignincellulose-hemicellulose complex's integrity. Other authors observed similar changes in wheat straw's morphology and structure caused by various pretreatments when imaging with a scanning electron microscope $[24,53]$. Due to significantly lower amounts of sugars and, hence, limited suitability for yeast growth experiments, as shown in Fig. 5a, conditions $\mathrm{P} 1$ and $\mathrm{P} 2$ were not analyzed in more detail by electron microscopy.

Wheat straw pretreated by miscellaneous methods has been used as a substrate for various kinds of microorganisms in order to biotechnologically produce biofuels $[23,54]$, microbial oils [51], other value-added chemicals [55-57], or enzymes [58, 59]. In recent years, $Y$. lipolytica has emerged as a popular host to produce a broad variety of substances by fermentation processes $[33,60]$. However, literature on using wheat straw as a substrate for growth of $Y$. lipolytica is sparse. Therefore, we aimed to analyze the suitability of the wheat straw hydrolysate generated by our approach as components of yeast growth media, in which they serve as sole carbon source for growth of Y. lipolytica. As shown in Fig. 5a, the yeast $Y$. lipolytica was able to grow in liquid media with $20 \%$ hydrolysates (v/v) from parameters P1-P4 as the sole carbon source. Hydrolysates from wheat straw steam-exploded with parameters P3 and P4 enabled the highest growth, which was photometrically measured as optical density. Due to significantly lower amounts of sugars, especially glucose, hydrolysates from parameters P1 and P2 resulted in reduced yeast growth. P5 was not included in the yeast growth studies, because of higher amounts of inhibitory substances, especially acetic acid.

In order to examine whether higher concentrations of hydrolysates act inhibitory for yeast growth, we added various amounts of P4-derived hydrolysates to synthetic media that already contained $20 \mathrm{~g} \mathrm{~L}^{-1}$ glucose as carbon source. As can be seen in Fig. 5b, replacing $\mathrm{dH}_{2} \mathrm{O}$ in media with hydrolysates did not negatively affect yeast growth. In contrast, adding hydrolysates next to glucose as co-substrate even increased overall yeast growth. Apparently, addition of hydrolysates provides more sugars, which results in higher $\mathrm{OD}_{600}$. However, above a certain percentage of hydrolysates, even addition of extra glucose as supplementary carbon source did not have a beneficial effect on yeast growth anymore. When comparing the $50 \%$ curves from Fig. $5 \mathrm{~b}$ and c, both have a nearly similar $\mathrm{OD}_{600}$ after $72 \mathrm{~h}$. Hence, when hydrolysates equal $50 \%(\mathrm{v} / \mathrm{v})$ or more of media, hydrolysates can fully substitute glucose as sole carbon source in minimal media.

More hydrolysate does not only mean more saccharides but also higher levels of inhibitory compounds. Therefore, we tested how much hydrolysate is needed and at the same time tolerated for optimal growth. To do so, Y. lipolytica was grown on media constituting of various amounts of hydrolysates as sole carbon source. As demonstrated in Fig. 5c, 
$Y$. lipolytica was able to grow well in media composed of up to $90 \%$ wheat straw hydrolysate (YNBH90 media) as sole carbon source. YNBH90 basically is a concentrated solution of salts, vitamins, trace elements, and ammonium sulfate as inorganic nitrogen source added to pure hydrolysate. Similarly, $Y$. lipolytica was able to grow on agave bagasse hydrolysate in concentrations up to $86 \%$ [61] and $50 \%$ corn stover hydrolysate [62]. When grown in high hydrolysate concentrations (especially in YNBH90 media), we could observe marginally slower growth in the early growth phase, which indicates that the yeasts had to adapt to this very high hydrolysate concentration. However, after 48-72 h, yeasts grown in YNBH80 and YNBH90 media reached the highest overall optical densities. When grown on wheat straw hydrolysate generated by the approach presented here, the maximum $Y$. lipolytica biomass yield after $72 \mathrm{~h}$ corresponded to $12.4 \mathrm{~g}$ dry cell weight $\mathrm{L}^{-1}$. Others found a maximum biomass of $7.4 \mathrm{~g} \mathrm{~L}^{-1}$ (reached after $144 \mathrm{~h}$ ) for $Y$. lipolytica grown on wheat straw hydrolysate [51]. Conversely, when grown for $120 \mathrm{~h}$ on rye straw hydrolysate, it was $3.35 \mathrm{~g} \mathrm{~L}^{-1}$ [63]. Concluding, our results suggest that wheat straw pretreated by the strategy developed in our study could be efficiently bio-converted into valuable platform chemicals or biofuels.

\section{Conclusions}

Impregnation of wheat straw with water in a 1:1 ratio for steam explosion improves total saccharide yield of subsequent enzymatic hydrolysis, while keeping the amount of inhibitory substances low. Generally, optimal parameters for this approach were modelled to be $200{ }^{\circ} \mathrm{C}$ for $9.2 \mathrm{~min}$. Experimental data demonstrated that, of all parameter combinations tested, steam explosion at $200{ }^{\circ} \mathrm{C}$ for $10 \mathrm{~min}$ resulted in the most-desired saccharide and inhibitor yields. Hydrolysates prepared by this approach are a suitable growth substrate for the biotechnologically used yeast $Y$. lipolytica.

Supplementary Information The online version contains supplementary material available at https://doi.org/10.1007/s13399-020-01266-z.

Acknowledgments We would like to thank Peter Preiner and Markus Gillich for technical assistance, and Manuel Selg for critically reviewing the manuscript.

Authors' contributions DA, ACS, and AZ conceived and designed research. DS, FH, and MR conducted experiments. All authors analyzed data. AZ wrote the manuscript. All authors read and approved the manuscript.

Funding Open Access funding provided by University of Applied Sciences Upper Austria. The project was funded by the European regional development fund under the grant agreement number 2015-132711.
Data availability All relevant data are supplied within the manuscript and supplementary information.

\section{Compliance with ethical standards}

Competing interests The authors declare that they have no competing interests.

Ethics approval Not applicable.

Consent to participate Not applicable.

Consent for publication All authors read the manuscript and expressed their consent for publication.

Code availability Not applicable.

Open Access This article is licensed under a Creative Commons Attribution 4.0 International License, which permits use, sharing, adaptation, distribution and reproduction in any medium or format, as long as you give appropriate credit to the original author(s) and the source, provide a link to the Creative Commons licence, and indicate if changes were made. The images or other third party material in this article are included in the article's Creative Commons licence, unless indicated otherwise in a credit line to the material. If material is not included in the article's Creative Commons licence and your intended use is not permitted by statutory regulation or exceeds the permitted use, you will need to obtain permission directly from the copyright holder. To view a copy of this licence, visit http://creativecommons.org/licenses/by/4.0/.

\section{References}

1. Isikgor FH, Becer CR (2015) Lignocellulosic biomass: a sustainable platform for the production of bio-based chemicals and polymers. Polym Chem 6:4497-4559. https://doi.org/10.1039/ c5py00263j

2. Batista Meneses D, Montes de Oca-Vásquez G, Vega-Baudrit JR et al (2020) Pretreatment methods of lignocellulosic wastes into value-added products: recent advances and possibilities. Biomass Convers Biorefine. https://doi.org/10.1007/s13399-020-00722-0

3. de Souza WR (2013) Microbial degradation of lignocellulosic biomass. In: Sustainable Degradation of Lignocellulosic Biomass Techniques, Applications and Commercialization. Anuj K. Chandel and Silvio Silvério da Silva. https://doi.org/10.5772/54325

4. Zheng Y, Pan Z, Zhang R (2009) Overview of biomass pretreatment for cellulosic ethanol production. Int J Agric Biol Eng 2:5168. https://doi.org/10.3965/j.issn.1934-6344.2009.03.051-068

5. Andlar M, Rezić T, Marđetko N et al (2018) Lignocellulose degradation: an overview of fungi and fungal enzymes involved in lignocellulose degradation. Eng Life Sci 18:768-778. https://doi.org/ 10.1002/elsc.201800039

6. Pothiraj C, Kanmani P, Balaji P (2006) Bioconversion of lignocellulose materials. Mycobiology 34:159-165. https://doi.org/10. 4489/myco.2006.34.4.159

7. Kumar R, Singh S, Singh OV (2008) Bioconversion of lignocellulosic biomass: biochemical and molecular perspectives. J Ind Microbiol Biotechnol 35:377-391. https://doi.org/10.1007/ s10295-008-0327-8

8. Baruah J, Nath BK, Sharma R et al (2018) Recent trends in the pretreatment of lignocellulosic biomass for value-added products. Front Energy Res 6. https://doi.org/10.3389/fenrg.2018.00141 
9. Steinbach D, Kruse A, Sauer J (2017) Pretreatment technologies of lignocellulosic biomass in water in view of furfural and 5hydroxymethylfurfural production- a review. Biomass Convers Biorefine 7:247-274. https://doi.org/10.1007/s13399-017-0243-0

10. Auxenfans T, Crônier D, Chabbert B, Paës G (2017) Understanding the structural and chemical changes of plant biomass following steam explosion pretreatment. Biotechnol Biofuels 10:1-16. https://doi.org/10.1186/s13068-017-0718-z

11. Pielhop T, Amgarten J, Von Rohr PR, Studer MH (2016) Steam explosion pretreatment of softwood: the effect of the explosive decompression on enzymatic digestibility. Biotechnol Biofuels 9: 152. https://doi.org/10.1186/s13068-016-0567-1

12. Pereira Ramos L (2003) The chemistry involved in the steam treatment of lignocellulosic materials. Quim Nova 26:863-871. https:// doi.org/10.1590/s0100-40422003000600015

13. Walker DJ, Gallagher J, Winters A et al (2018) Process optimization of steam explosion parameters on multiple lignocellulosic biomass using Taguchi method-a critical appraisal. Front Energy Res 6:46. https://doi.org/10.3389/fenrg.2018.00046

14. Overend R, Chornet E, Gascoigne J et al (1987) Fractionation of lignocellulosics by steam-aqueous pretreatments. Philos Trans R Soc London Ser A, Math Phys Sci 321:523-536. https://doi.org/ 10.1098/rsta.1987.0029

15. Jönsson LJ, Alriksson B, Nilvebrant NO (2013) Bioconversion of lignocellulose: inhibitors and detoxification. Biotechnol Biofuels 6: 16. https://doi.org/10.1186/1754-6834-6-16

16. Zimbardi F, Viola E, Nanna F et al (2007) Acid impregnation and steam explosion of corn stover in batch processes. Ind Crop Prod 26:195-206. https://doi.org/10.1016/j.indcrop.2007.03.005

17. Eklund R, Galbe M, Zacchi G (1995) The influence of SO2 and $\mathrm{H} 2 \mathrm{SO} 4$ impregnation of willow prior to steam pretreatment. Bioresour Technol 52:225-229. https://doi.org/10.1016/09608524(95)00042-D

18. Sørensen A, Teller PJ, Hilstrøm T, Ahring BK (2008) Hydrolysis of Miscanthus for bioethanol production using dilute acid presoaking combined with wet explosion pre-treatment and enzymatic treatment. Bioresour Technol 99:6602-6607. https://doi.org/10.1016/j. biortech.2007.09.091

19. Mihiretu GT, Chimphango AF, Görgens JF (2019) Steam explosion pre-treatment of alkali-impregnated lignocelluloses for hemicelluloses extraction and improved digestibility. Bioresour Technol 294. https://doi.org/10.1016/j.biortech.2019.122121

20. Ouyang X, Chen L, Zhang S et al (2018) Effect of simultaneous steam explosion and alkaline depolymerization on corncob lignin and cellulose structure. Chem Biochem Eng Q 32:177-189. https:// doi.org/10.15255/CABEQ.2017.1251

21. Scarlat N, Martinov M, Dallemand JF (2010) Assessment of the availability of agricultural crop residues in the European Union: potential and limitations for bioenergy use. Waste Manag 30: 1889-1897. https://doi.org/10.1016/j.wasman.2010.04.016

22. Searle S, Malins C (2013) Availability of cellulosic residues and wastes in the EU. https://www.semanticscholar.org/paper/AVAILABILITYOF-CELLULOSIC-RESIDUES-AND-WASTES-IN-Searle-Malins/ 2f5e193d3b15f7954959f2b60844af43f5f9895e

23. Talebnia F, Karakashev D, Angelidaki I (2010) Production of bioethanol from wheat straw: an overview on pretreatment, hydrolysis and fermentation. Bioresour Technol 101:4744-4753. https:// doi.org/10.1016/j.biortech.2009.11.080

24. Zheng Q, Zhou T, Wang Y et al (2018) Pretreatment of wheat straw leads to structural changes and improved enzymatic hydrolysis. Sci Rep 8. https://doi.org/10.1038/s41598-018-19517-5

25. Tozluoğlu A, Özyurek Ö, Çöpür Y, Özdemir H (2015) Integrated production of biofilm, bioethanol, and papermaking pulp from wheat straw. BioResources 10:7834-7853. https://doi.org/10. 15376/biores.10.4.7834-7853
26. Cui Z, Shi J, Li Y (2011) Solid-state anaerobic digestion of spent wheat straw from horse stall. Bioresour Technol 102:9432-9437. https://doi.org/10.1016/j.biortech.2011.07.062

27. Thakur S, Shrivastava B, Ingale S et al (2013) Degradation and selective ligninolysis of wheat straw and banana stem for an efficient bioethanol production using fungal and chemical pretreatment. 3 Biotech 3:365-372. https://doi.org/10.1007/s13205-0120102-4

28. Thomsen MH, Thygesen A, Jørgensen H, et al (2006) Preliminary results on optimization of pilot scale pretreatment of wheat straw used in coproduction of bioethanol and electricity. In: McMillan J.D., Adney W.S., Mielenz J.R., Klasson K.T. (eds) TwentySeventh Symposium on Biotechnology for Fuels and Chemicals. ABAB Symposium. Humana Press. pp 129-132. https://doi.org/10. 1007/978-1-59745-268-7_37

29. Fang H, Deng J, Zhang X (2011) Continuous steam explosion of wheat straw by high pressure mechanical refining system to produce sugars for bioconversion. BioResources 6:4468-4480. https:// doi.org/10.15376/biores.6.4.4468-4480

30. Ballesteros I, Negro MJ, Oliva JM et al (2006) Ethanol production from steam-explosion pretreated wheat straw. Appl Biochem Biotechnol 130:496-508. https://doi.org/10.1385/ABAB:130:1: 496

31. Monschein M, Nidetzky B (2016) Effect of pretreatment severity in continuous steam explosion on enzymatic conversion of wheat straw: evidence from kinetic analysis of hydrolysis time courses. Bioresour Technol 200:287-296. https://doi.org/10.1016/j. biortech.2015.10.020

32. Alvira P, Negro MJ, Ballesteros I et al (2016) Steam explosion for wheat straw pretreatment for sugars production. Bioethanol 2:6675. https://doi.org/10.1515/bioeth-2016-0003

33. Miller KK, Alper HS (2019) Yarrowia lipolytica: more than an oleaginous workhorse. Appl Microbiol Biotechnol 103:92519262. https://doi.org/10.1007/s00253-019-10200-x

34. Liu HH, Ji XJ, Huang H (2015) Biotechnological applications of Yarrowia lipolytica: past, present and future. Biotechnol Adv 33: 1522-1546. https://doi.org/10.1016/j.biotechadv.2015.07.010

35. Eisenhuber K, Krennhuber K, Steinmüller V, Jäger A (2013) Comparison of different pre-treatment methods for separating hemicellulose from straw during lignocellulose bioethanol production. Energy Procedia 40:172-181. https://doi.org/10.1016/j. egypro.2013.08.021

36. Carvalheiro F, Silva-Fernandes T, Duarte LC, Gírio FM (2009) Wheat straw autohydrolysis: process optimization and products characterization. Appl Biochem Biotechnol 153:84-93. https:// doi.org/10.1007/s12010-008-8448-0

37. Wang K, Chen J, Sun SN, Sun RC (2015) Steam explosion. In: Pandey A, Negi S, Binod P, Larroche C (eds) Pretreatment of Biomass. pp 75-104. Elsevier: Amsterdam

38. Merklein K, Fong SS, Deng Y (2016) Biomass utilization. In: Biotechnology for Biofuel Production and Optimization. pp 291324

39. Bassani A, Fiorentini C, Vadivel V et al (2020) Implementation of auto-hydrolysis process for the recovery of antioxidants and cellulose from wheat straw. Appl Sci 10. https://doi.org/10.3390/ app10176112

40. Jung JY, Ha SY, Yang JK (2019) Effect of water-impregnation on steam explosion of Pinus densiflora. J Korean Wood Sci Technol 47:189-199. https://doi.org/10.5658/WOOD.2019.47.2.189

41. Michalak L, Knutsen SH, Aarum I, Westereng B (2018) Effects of $\mathrm{pH}$ on steam explosion extraction of acetylated galactoglucomannan from Norway spruce. Biotechnol Biofuels 11. https://doi.org/10.1186/s13068-018-1300-z

42. Jönsson LJ, Martín C (2016) Pretreatment of lignocellulose: formation of inhibitory by-products and strategies for minimizing their 
effects. Bioresour Technol 199:103-112. https://oi.org/10.1016/j. biortech.2015.10.009

43. Jeong SY, Lee JW (2015) Hydrothermal treatment. In: Pandey A, Negi S, Binod P, Larroche C (eds) Pretreatment of Biomass. Elsevier: Amsterdam pp. 61-74

44. Coz A, Llano T, Cifrián E et al (2016) Physico-chemical alternatives in lignocellulosic materials in relation to the kind of component for fermenting purposes. Materials (Basel) 9:574. https://doi. org/10.3390/MA9070574

45. Junior CS, Milagres AMF, Ferraz A, Carvalho W (2013) The effects of lignin removal and drying on the porosity and enzymatic hydrolysis of sugarcane bagasse. Cellulose 20:3165-3177. https:// doi.org/10.1007/s10570-013-0032-2

46. Mo W, Ke K, Shen X, Li B (2020) The influence of "thermal drying pretreatment" on enzymatic hydrolysis of cellulose and xylan in poplar fibers with high lignin content. Carbohydr Polym. https:// doi.org/10.1016/j.carbpol.2019.115400

47. Koo B, Jo J, Cho SM (2020) Drying effect on enzymatic hydrolysis of cellulose associated with porosity and crystallinity. Appl Sci 10. https://doi.org/10.3390/app10165545

48. Liu ZL, Slininger PJ, Dien BS et al (2004) Adaptive response of yeasts to furfural and 5-hydroxymethylfurfural and new chemical evidence for HMF conversion to 2,5-bis-hydroxymethylfuran. J Ind Microbiol Biotechnol 31:345-352. https://doi.org/10.1007/s10295004-0148-3

49. Taherzadeh MJ, Gustafsson L, Niklasson C, Lidén G (2000) Physiological effects of 5-hydroxymethylfurfural on Saccharomyces cerevisiae. Appl Microbiol Biotechnol 53:701708. https://doi.org/10.1007/s002530000328

50. Sanchez B, Bautista J (1988) Effects of furfural and 5hydroxymethylfurfural on the fermentation of Saccharomyces cerevisiae and biomass production from Candida guilliermondii. Enzym Microb Technol 10:315-318. https://doi.org/10.1016/ 0141-0229(88)90135-4

51. Yu X, Zheng Y, Dorgan KM, Chen S (2011) Oil production by oleaginous yeasts using the hydrolysate from pretreatment of wheat straw with dilute sulfuric acid. Bioresour Technol 102:6134-6140. https://doi.org/10.1016/j.biortech.2011.02.081

52. Russ A, Fišerová M, Letko M, Opálen E (2016) Effect of steam explosion temperature on wheat straw enzymatic hydrolysis. Wood Res 61:65-74

53. Momayez F, Karimi K, Sárvári Horváth I (2019) Sustainable and efficient sugar production from wheat straw by pretreatment with biogas digestate. RSC Adv (47):27692-27701. https://doi.org/10. $1039 / \mathrm{c} 9 \mathrm{ra} 05285 \mathrm{~b}$
54. Passoth V, Sandgren M (2019) Biofuel production from straw hydrolysates: current achievements and perspectives. Appl Microbiol Biotechnol 103:5105-5116. https://doi.org/10.1007/s00253-01909863-3

55. Canilha L, Almeida E, Silva JB, Felipe MGA, Carvalho W (2003) Batch xylitol production from wheat straw hemicellulosic hydrolysate using Candida guilliermondii in a stirred tank reactor. Biotechnol Lett 25:1811-1814. https://doi.org/10.1023/A: 1026288705215

56. Liu Z, Feist AM, Dragone G, Mussatto SI (2020) Lipid and carotenoid production from wheat straw hydrolysates by different oleaginous yeasts. J Clean Prod 249:1 19308. https://doi.org/10.1016/j. jclepro.2019.119308

57. Cizeikiene D, Juodeikiene G, Damasius J (2018) Use of wheat straw biomass in production of L-lactic acid applying biocatalysis and combined lactic acid bacteria strains belonging to the genus Lactobacillus. Biocatal Agric Biotechnol 15:185-191. https://doi. org/10.1016/j.bcab.2018.06.015

58. Pensupa N, Jin M, Kokolski M et al (2013) A solid state fungal fermentation-based strategy for the hydrolysis of wheat straw. Bioresour Technol 149:261-267. https://doi.org/10.1016/j. biortech.2013.09.061

59. Shahryari Z, Fazaelipoor MH, Setoodeh P et al (2018) Utilization of wheat straw for fungal phytase production. Int $\mathrm{J}$ Recycl Org Waste Agric 7:345-355. https://doi.org/10.1007/s40093-018-0220-z

60. Madzak C (2018) Engineering Yarrowia lipolytica for use in biotechnological applications: a review of major achievements and recent innovations. Mol Biotechnol 60:621-635. https://doi.org/ 10.1007/s12033-018-0093-4

61. Niehus X, Crutz-Le Coq AM, Sandoval G et al (2018) Engineering Yarrowia lipolytica to enhance lipid production from lignocellulosic materials. Biotechnol Biofuels. https://doi.org/10.1186/s13068018-1010-6

62. Yao F, Liu SC, Wang DN et al (2020) Engineering oleaginous yeast Yarrowia lipolytica for enhanced limonene production from xylose and lignocellulosic hydrolysate. FEMS Yeast Res 20. https://doi. org/10.1093/femsyr/foaa046

63. Drzymała K, Mirończuk AM, Pietrzak W, Dobrowolski A (2020) Rye and oat agricultural wastes as substrate candidates for biomass production of the non-conventional yeast Yarrowia lipolytica. Sustain 12. https://doi.org/10.3390/su12187704

Publisher's note Springer Nature remains neutral with regard to jurisdictional claims in published maps and institutional affiliations. 